\title{
The flavor and taste of cereal Chinese vinegars
}

\author{
Paolo Giudici, ${ }^{1}$ Giuseppe Corradini, ${ }^{1}$ Tommaso Bonciani, ${ }^{1}$ Jiajia Wu, ${ }^{2}$ Fusheng Chen, ${ }^{3}$ \\ Federico Lemmetti ${ }^{1}$
${ }^{1}$ Unimore Microbial Culture Collection, Department of Life Sciences, University of Modena and Reggio Emilia, Italy; ${ }^{2}$ College of Life Science, China Jiliang University, Hang Zhou, China; ${ }^{3}$ College of Food Science and Technology, Huazhong Agricultural University, Wuhan, China

\begin{abstract}
A lexicon for describing Chinese cereal vinegars (CCVs) was developed using trained panels of tasters that defined and referenced 23 significant olfactory descriptors, in concert with taste and trigeminal sensation. The sensory analysis was performed on 27 samples, representative of the five well-known Chinese provinces producing vinegar: Shanxi, Jiangsu, Sichuan, Fujian and Tianjin. Several aromatic descriptors define the sensory lexicon, e.g.: licorice, chocolate, meat broth, toasted, walnut, yogurt, coffee; together with five basic tastes, such as acid, sweet, salty, umami and bitter; and four for trigeminal sensations, astringent, pungent, metallic, and piquant (spicy). This preliminary study will be useful to CCVs producers because this lexicon reliably differentiates and characterizes this kind of vinegar.
\end{abstract}

\section{Introduction}

China has a very long tradition in the production of grain vinegars. ${ }^{1}$ Chinese vinegars differ for the type of cereals and legumes

Correspondence: Paolo Giudici, Unimore Microbial Culture Collection, Department of Life Sciences, University of Modena and Reggio Emilia, via Giovanni Amendola 2, 42122 Reggio Emilia, Italy.

Tel./Fax: +39.0522.522057 / +39.0522.522026.

E-mail: paolo.giudici@unimore.it

Key words: Cereal vinegar; Chinese vinegar; sensory analysis; flavor descriptors; sensory vocabulary.

Contributions: PG conceived and wrote the article; TB reviewed and coordinated the writing procedure; FL and GC elaborated the sensory data; TB, GC and FL organized and coordinated the sessions of sensory analysis; JW and FC handled the section about vinegar description.

Received for publication: 15 November 2016.

Revision received: 27 December 2016.

Accepted for publication: 10 January 2017.

This work is licensed under a Creative Commons Attribution NonCommercial 4.0 License (CC BY-NC 4.0).

(C) Copyright P. Giudici et al., 2017

Licensee PAGEPress, Italy

Acetic Acid Bacteria 2017; 6:6370

doi:10.4081/aab.2017.6370 used as raw material, for the production technology and the more or less extended aging. 2,3 The most widespread and well established vinegars come from four districts and differ for the ingredients: Fujian (water, glutinous rice, red yeast rice, sugar, salt); Jiangsu (water, glutinous rice, bran, sugar, salt); Shanxi (sorghum, barley, bran, chaff, pea, salt, water); Sichuan (bran, wheat, rice, glutinous rice) and Tianjin (water, sorghum, millet, wheat, pea). The production technology has many aspects in common, but also few important differences. Among them, heat treatment or toasting (at least on part of the product) even in the presence of chaff; concentration in open jar or in special evaporation chambers (Shanxi aged vinegar and Zhenjing aromatic vinegar). Furthermore, in the past, in the region of Shanxi and Tianjin, vinegar was concentrated during the harsh winter, removing the ice crystals. All these differences in raw material and technologies suggest marked difference among vinegars, or between vinegars of the same type but otherwise aged. For a more complete and articulated discussion on the production technologies of cereal vinegars, refer to the literature. , $^{1,4}$

The sensory analysis of vinegar is not easy for at least two reasons: the strong aggressiveness of acetic acid on the sensorial papillae $e^{5}$ and the absence of definition of the sensory attributes of vinegar. ${ }^{6}$ To overcome the first hurdle, it is necessary to set a tasting procedure to preserve the tasting abilities of the panelists, the literature on the topic is large and well documented..$^{6-8}$

Regarding the sensory attributes, there is shared a general vocabulary to describe the sensory properties of vinegars and in particular for Jerez vinegar, ${ }^{9}$ but few data, in our knowledge, on cereal vinegars and all on Japanese ones. ${ }^{10}$ From the literature on wine vinegars, we can derive some characteristic and common indicators referring to vinegars. ${ }^{11}$ The first is, without a doubt, the pungency, a more tactile feel and smell; other terms used frequently are: glue, alcoholic, vinous, raisins, woody, cloves, citrus, red fruits, vanilla, sweet aroma, bitter almond, medicine, apple, and coconut. Some attributes are decisively negative, such as old/leather, rancid, bacteria, cheese and sawdust/wood..$^{5,8}$

A shared vocabulary or lexicon is a necessary condition for proper sensory analysis of any food, ${ }^{12,13}$ because lexica are the common language for describing products. The purpose of a lexicon is four-fold: i) to collect a product frame of reference; ii) generate the terms; iii) review references and examples; iv) develop a final descriptor list. Numerous lexica have been developed for a variety of products such as: cheddar cheese; ${ }^{14}$ peanut; for handfeel properties; ${ }^{15}$ soymilks; ${ }^{16}$ floral honey; ${ }^{17}$ green tea. ${ }^{18}$ The purpose of the current study was to develop a comprehensive sensory lexicon for Chinese cereal vinegars, developing an appropriate sensory terminology. 


\section{Materials and Methods}

\section{Samples}

Shanxi Aged Vinegar Group Co. Ltd. provided 27 samples from the most popular areas of Chinese cereal vinegar. They have been chosen to represent the population of industrial vinegars available on the market. They also differ for age, acidity, sugar content and production technology. Table 1 shows the complete list of vinegars.

\section{Sensory evaluation Panel}

Seventy trained Italian judges evaluated the samples of CCVs for lexicon development. Four panels from university, industry and cultural association were assembled. The panels consisted of 21 females and 49 males. The greatest part of the judges was qualified as tasters, only someone with specific vinegar tasting experiences. The diverse backgrounds of panelists were effective in generating a comprehensive initial language for comparison with the preliminary descriptor list. Nothing was told to judges about the CCVs (e.g., origin and method of processing), in order to reduce any possible biases. The four tasting sessions included up to a maximum of 20 judges per session. Each member has never tasted the same sample twice, then not all the members have tasted all the samples. The tasting procedure was conducted on samples obscured with aluminum foil to avoid the influence of visual observation on the olfactory and taste perceptions. Vinegar samples of about $3 \mathrm{~mL}$ were served in small glasses. The glasses were closed with their lids and left at room temperature for at least 10 minutes. The judges were informed of the sensory techniques to assess aroma and flavor attributes according to. ${ }^{19}$

The judges evaluated each CCV individually: the aim of the sensory test was not to assess the intensity of each descriptor but to understand which descriptors were mainly perceived in CCV as a category of products. We provided the tasters with notebooks and we asked them to write down all the perceived descriptors, both the taste- and flavor-related ones. After the tasting, the panel leaders led a discussion to come to agreement on the descriptors present in the CCV sample. As the panel agreed on descriptors, they began to define and reference each of them. The panel was asked to be as specific as possible in identifying descriptors.

\section{Results and Discussion}

The first objective of the research was to identify all possible descriptors of the CCVs, regardless of the type and area of origin. For this purpose, the panel members were asked to describe the aromas and, later, taste samples. Each vinegar has been tasted by at least 20 judges. At the end of each tasting session, the panel leaders steered the discussion to standardize the meaning of terms used and, not secondarily, to group the terms based on a common meaning among the judges.

However, it should be considered that the panels were four and led by different leaders and with different judges. For this reason, it was not possible to get a vocabulary entirely shared by all the tasters in one single step. The results of this first aggregation are shown in Table 2, where it is possible to notice some significant similarities between some of the descriptors highlighted by the different panels. For example, different panel used respectively Anise and Licorice as a grouping descriptor of the same terms (Table 2). This is the reason why a second fine-tuning of descriptors was necessary, with few additional groupings. To do this, the panel leaders and a group of trained judges made a further aggregation. This type of reduction is normal during the initial training section. ${ }^{20}$ The taste of CCVs covered all the five well known sensations: sweet, bitter, acid, salty and umami; trigeminal sensations were spicy, pungent, astringent and metallic.

\section{The smell of Chinese cereal vinegars}

The most frequent terms grouped under a single descriptor according to their meaning are shown in Figure 1. The frequency, calculated by normalizing to 100 , is the number of judges who have felt a particular descriptor in at least one of the vinegars of his sensorial session. Figure 1 shows distributions of the descriptors found in $\mathrm{CCV}$. Whereas no judge has tasted more than nine CCVs samples, the very high relative frequencies can be taken as evidence of specific descriptors for CCVs.

The distribution histogram clearly shows that some descriptors are really frequent in CCVs, in particular chocolate, toasted, meat broth, licorice, walnut, yogurt and others. Nevertheless, they do not give any information about the different type of vinegars. In order to highlight olfactory differences between the diverse vinegars, the data were broken down and grouped by brand and/or origin (data not shown). The five vinegars coming from the Shanxi (samples A, B, C, D, E) showed different sensory profiles based on detection frequency. In particular, the greatest part of judges who tasted vinegar Donghu (sample A) have perceived walnut notes and meat broth as prevalent olfactory descriptors. Meiogee vinegar was characterized by a strong walnut together with leather and caramel. The $C$ series (Zilin) has a strong scent of meat broth, flour and walnut; all the three flavors tend to be detected at a higher frequency in the more aged vinegars. An intense aroma of licorice was recognized in the $D$ samples (Ninghua fu) and $E$ (Shuita); the fragrance was perceived by $100 \%$ of the judges who have tasted the samples of the two oldest vinegars. Younger samples of the same vinegar also had the same aromas at a lower frequency and other smells like meat broth, smoked, fruit and glue. The three $F$ samples (Boaning vinegar) have a strong smell of meat broth, yogurt and fruit, the last one decreases with the ageing. The three samples of Yongchun (G) aged vinegar are characterized by a smell of fruit, which decreases with the ageing, to leave more space to the odor of yogurt and glue. The Henshun vinegars $(\mathrm{H})$ are well characterized by scent of meat broth that increases with the ageing. The oldest Tianli Duliu samples (I) have a strong smell of chocolate and toasted, while in the youngest yogurt, leather and smoked flavors prevail.

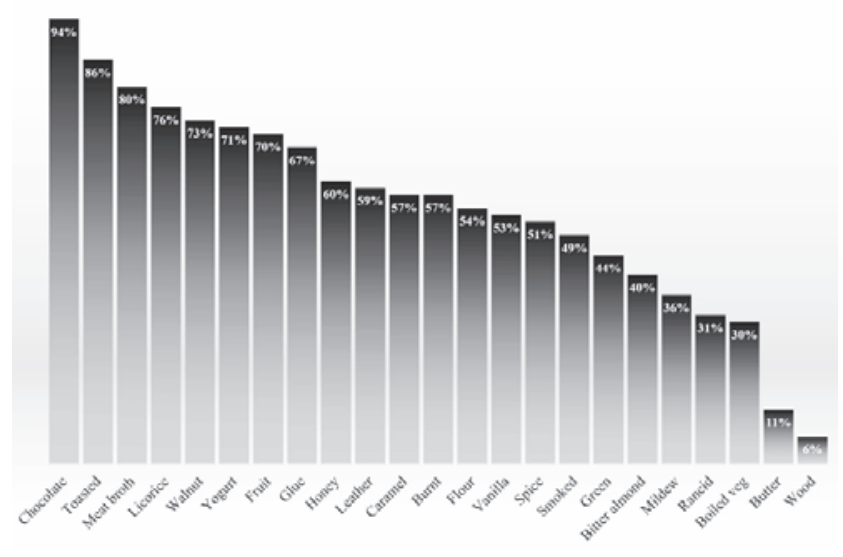

Figure 1. Percentage of judges who have felt at least one cereal Chinese vinegar with one or more of the descriptors listed. 
Table 1. 样品信息 - Sample information.

\begin{tabular}{|c|c|c|c|c|c|}
\hline 地区 & 要需 & 祭貫 & 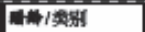 & 度 & in \\
\hline District & Brand & 10 & $\begin{array}{l}\text { Aging and/or } \\
\text { Type }\end{array}$ & Acidity* & Raw Materiel \\
\hline 山'A & 获站 & & $\begin{array}{l}8 \text { 年考陈艄 } 8 \\
\text { years }\end{array}$ & & 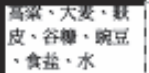 \\
\hline \multirow[t]{17}{*}{ Shanxi } & Donghu & A1 & $\begin{array}{l}\text { Shanxi Mature } \\
\text { Vinegar (SMV) }\end{array}$ & 8 & \begin{tabular}{l|} 
Sorghum, \\
barley, bran, \\
chaff, pea, salt, \\
water
\end{tabular} \\
\hline & & A2 & $\begin{array}{l}\text { 5年考陳重 } 5 \\
\text { years SMV }\end{array}$ & 8 & \\
\hline & & A3 & $\begin{array}{l}3 \text { 年考陳筩 } 3 \\
\text { years SMV }\end{array}$ & 6 & \\
\hline & 狈和居 & 81 & $\begin{array}{l}10 \text { 年考陳保 } 10 \\
\text { years SMV }\end{array}$ & 7 & \\
\hline & Meiogee & 82 & 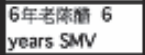 & 6.5 & \\
\hline & & 83 & 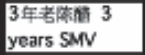 & 6 & \\
\hline & 慗休 & C1 & $\begin{array}{l}\text { 8年考陈船 } 8 \\
\text { years }\end{array}$ & 6.5 & \\
\hline & Zilin & & SMN & & \\
\hline & & $\mathrm{C} 2$ & $\begin{array}{l}\text { 6年考畨 } 6 \\
\text { years SMN }\end{array}$ & 6 & \\
\hline & & $\mathrm{C} 3$ & $\begin{array}{l}\text { 3年考漛 } 3 \\
\text { years SMN }\end{array}$ & 4.5 & \\
\hline & 广化 & 01 & $\begin{array}{l}10 \text { 年考漛 } 10 \\
\text { years SMV }\end{array}$ & 6 & \\
\hline & Ninghua Fu & D2 & $\begin{array}{l}\text { 5年考陸諙 } 5 \\
\text { years SAMV }\end{array}$ & 6 & \\
\hline & & D3 & 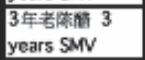 & 5.5 & \\
\hline & 永㤏 & E1 & $\begin{array}{l}8 \text { 年考陈角 } 8 \\
\text { years }\end{array}$ & 6 & \\
\hline & Shuita & & SMN & & \\
\hline & & E2 & $\begin{array}{l}\text { 5年考䧒奥 } 5 \\
\text { years SMN }\end{array}$ & 6 & \\
\hline & & E3 & $\begin{array}{l}3 \text { 年考陳魚 } 3 \\
\text { years SMV }\end{array}$ & 4.5 & \\
\hline 딴) & 保宁 & $\mathrm{F} 1$ & 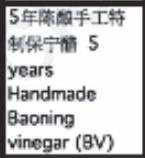 & 6 & $\begin{array}{l}\text { 数皮、小麦·大 } \\
\text { 米・楮米·水 }\end{array}$ \\
\hline \multirow[t]{2}{*}{ Sichuan } & Baoning & F2 & 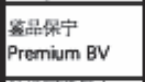 & 6 & $\begin{array}{l}\text { Bran, wheat, } \\
\text { rice, glutinous } \\
\text { rice, water }\end{array}$ \\
\hline & & F3 & 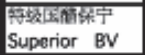 & 6 & \\
\hline 䄚垏 & 袜青 & & $\begin{array}{l}10 \text { 年水 } \\
10 \text { years }\end{array}$ & & 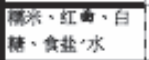 \\
\hline \multirow[t]{3}{*}{ Fujan } & Yongchun & G1 & $\begin{array}{l}\text { Yongchun aged } \\
\text { vinegar } \\
\text { (YAV) }\end{array}$ & 6.5 & $\begin{array}{l}\text { Glutinous rice, } \\
\text { anka, sugar, } \\
\text { salt, water }\end{array}$ \\
\hline & & G2 & 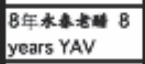 & 6.5 & 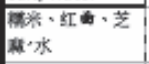 \\
\hline & & G3 & $\begin{array}{l}\text { 3年-14te } 3 \\
\text { years YAV }\end{array}$ & 6.5 & $\begin{array}{l}\text { Glutinous rice, } \\
\text { arka, sesame, } \\
\text { water }\end{array}$ \\
\hline 红多 & 㨁省 & H1 & $\begin{array}{l}\text { 6年滦的和 } 6 \\
\text { years Zhenjiang } \\
\text { aged aromatic } \\
\text { vinegar (ZAAV) }\end{array}$ & 6.4 & 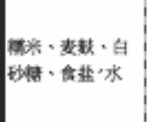 \\
\hline \multirow[t]{2}{*}{ Jiangsu } & Henshun & $\mathrm{H} 2$ & 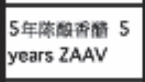 & 5.5 & $\begin{array}{l}\text { Glutinous rice, } \\
\text { bran, sugar, } \\
\text { salt, water }\end{array}$ \\
\hline & & H3 & 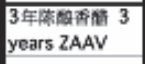 & $5.5-6.0$ & \\
\hline 天冿 & 天计的港 & 11 & 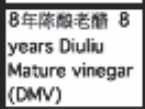 & 5 & 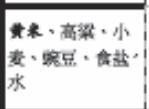 \\
\hline \multirow[t]{3}{*}{ Tianjin } & Tranli Duliu & 12 & $\begin{array}{l}5 \text { 年除的考 } 5 \\
\text { years DMN }\end{array}$ & 5 & $\begin{array}{l}\text { millet, } \\
\text { sorghum, } \\
\text { wheat, pea, } \\
\text { salt, water }\end{array}$ \\
\hline & & & & & 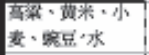 \\
\hline & & 13 & years DMV & 4 & $\begin{array}{l}\text { Sorghum, } \\
\text { millet, wheat, } \\
\text { pea, water }\end{array}$ \\
\hline
\end{tabular}


In general, the tasted vinegars showed a complex aroma, but with one or few dominant odors that make them recognizable even to tasters unfamiliar with CCVs. This is a very important point because, on the one hand, emphasizes that CCVs share some sensory characteristics; on the other hand, every single vinegar differs for specific dominant notes.

\section{The taste of Chinese cereal vinegars}

Most of the judges perceived the 5 taste descriptors in all tasted vinegars, while only a few judges have not detected all descriptors in all vinegars. This remark is the same for trigeminal sensations. However, the intensity of taste perception for each descriptor varied greatly. Judges defined their own taste sensations with a threedegree score: high, medium and low/absent. In order to render the results in graphical form, the descriptive judgments have been converted to values, respectively $1=$ high; $0.5=$ medium and $0=$ low / absent. To get the final score of any descriptor the following formula was applied: $[(1 \times N 1+0.5 \times N 2+0 \times N 3) \times 100) /(\mathrm{N} 1+\mathrm{N} 2+\mathrm{N} 3)]$, where N1, N2, and N3 are the number of judges who evaluated, respectively, high, medium or low the vinegar for that specific descriptor. In short, when the score is 100 all the judges find the vinegar at the highest level for that specific descriptor.

Figures 2, 3 and 4 show the radar chart of the taste of CCVs, grouped accordingly to their aging. Similarly to what observed for olfactory sensations, the tasted vinegars show shared taste impressions, while important differences were found among the different aged vinegars. For example, the trigeminal sensation spicy is frequently felt in aged and medium aged vinegars, but not in the youngest ones. It is important to remember that spicy refers to the trigeminal nerve irritation caused by spicy foods such as chili. The sensations of pungent and astringent are quite frequent and felt at high level, especially the first one, that is due to acetic acid content of the vinegars. The astringency is more common in young vinegars and it decreases with the ageing process. Regarding the taste, bitter is more common in medium-aged vinegar but not for all the vinegars: only the sample $\mathrm{H} 2$ and $\mathrm{F} 2$ show a remarkable bitter taste. In general, the main taste descriptors of $\mathrm{CCVs}$ are acid and salted, while sweet and umami are less frequent and rarely felt at high levels. The salted sensation is probably due to the added sodium chloride, but the contribute of other molecules, such as amino acids from raw materials, should not to be excluded.

\section{Conclusions}

In the present work, a preliminary descriptive language for CCVs was identified and proposed: 23 main olfactory descriptors were associated to the products, which were also characterized according to the yielded trigeminal sensations. CCVs share some olfactory descriptors such as: meat broth, toasted, walnut, chocolate and others, which are more peculiar for specific vinegars. Regarding the taste, acid and salted are the two descriptors universally present in all vinegars, while sweet is rarely felt and, when perceived, it is at very low intensity. The bitterness is peculiar of two medium matured vinegars and coming from two different districts. The last taste umami is poorly represented; this last observation is in apparent contradiction with the high frequency of the olfactory perception of meat broth. Indeed, it is a reasonable assumption that umami taste and broth smell are linked sensorial sensations. The reason why these two sensations resulted uncorrelated could be due to the judges' cultural background or, more probably, to the fact that many judges felt umami as a regular savory/salted taste. Trigeminal pungent sensation is a common trait

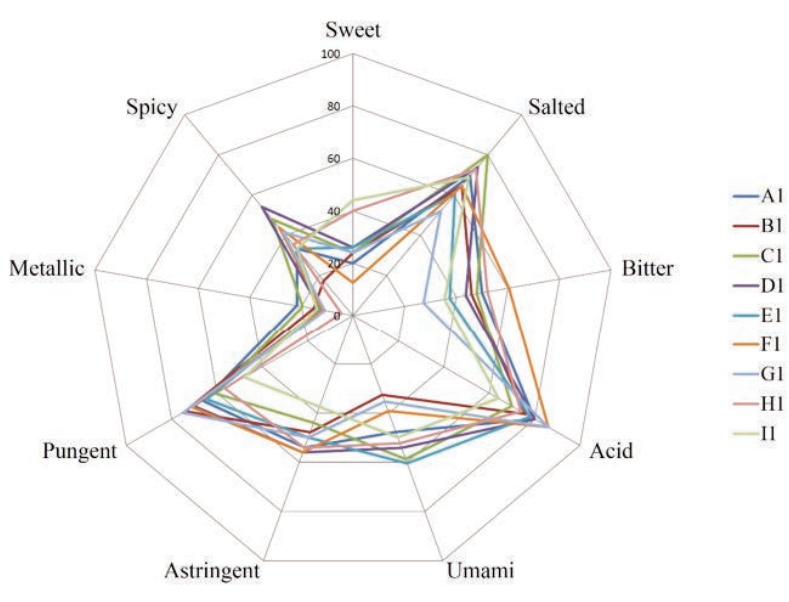

Figure 2. Radar chart of taste and trigeminal sensations of the most aged Chinese Cereal Vinegars. The capital letter refers to the different samples as reported in material and methods.

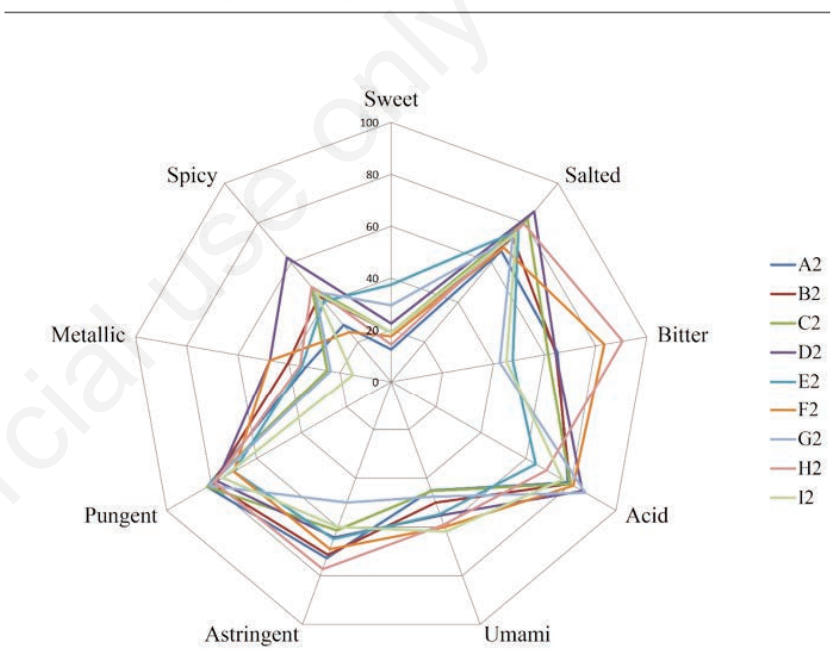

Figure 3. Radar chart of taste and trigeminal sensations of the medium-aged Chinese Cereal Vinegars. The capital letter refers to the different samples as reported in material and methods.

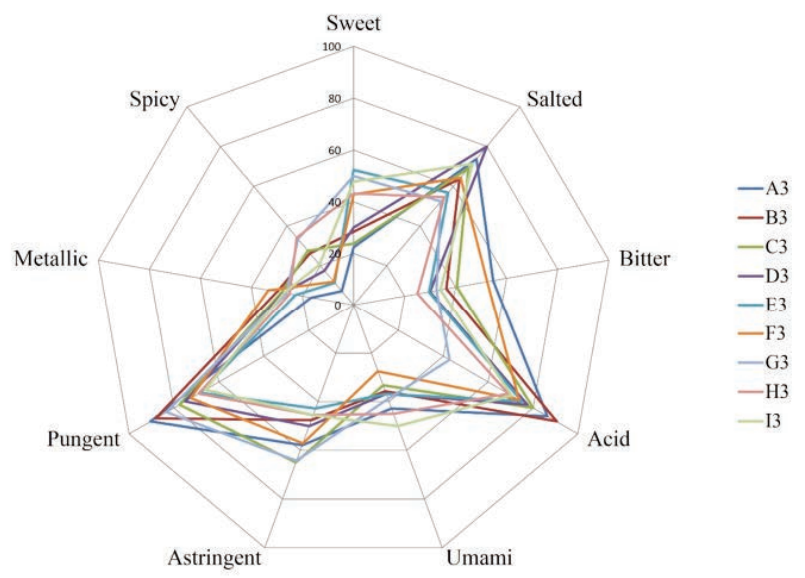

Figure 4. Radar chart of taste and trigeminal sensations of the less aged Chinese Cereal Vinegars. The capital letter refers to the different samples as reported in material and methods. 
of all the CCVs, sometimes it is perceived very high and at other times it is more balanced. Whereas, spicy is less frequent and related to specific vinegars. Notwithstanding that this is a preliminary lexicon on the sensorial traits of CCVs, its value is due to the high number of trained judges with experiences on food and beverage, but without any experiences of CCVs. The absence of previous experience on CCVs is a guarantee of absolute independence in the sensorial perception during tasting. As it is well known, the inde- pendence of judgment is a basic requirement for sensory evaluation. ${ }^{21}$ In our opinion, this basic lexicon could help in different points of the production chain and in the commercialization of CCVs: i) to improve the procedures of quality control; ii) to give useful sensory data to evaluate processes and raw materials; iii) to better compare analytical data and sensory properties; iv) to identify flavor characteristics that appeal to particular subsets of the global marketplace.

Table 2. Most frequent olfactory descriptors and terms used by the judges of the four different panels.

\begin{tabular}{|c|c|c|c|}
\hline Descriptors & $\begin{array}{l}\text { Terms used to describe sensorial attribute by different judges } \\
\text { and grouped under common descriptors defined during } \\
\text { the different panel discussions }\end{array}$ & No. of judges & $\%$ \\
\hline Walnut & Hazelnut & 51 & $73 \%$ \\
\hline Licorice & Anise, Mint, Ginger, Tarragon, Dry orange peel, Lemon, Menthol & 51 & $73 \%$ \\
\hline Soy sauce & Broth, Cooked, Fish, Umami & 46 & $66 \%$ \\
\hline Hay & Cocoa, Coffee, The, Chocolate, Tobacco & 44 & $63 \%$ \\
\hline Toasted & Bread crust, Bread, Alcohol, Flour, Yeast & 40 & $57 \%$ \\
\hline Corn silage & Acid, Olive, Pungent, Cheese, Vomit, Sweat, Milk, Yogurt & 40 & $57 \%$ \\
\hline Burnt & & 40 & $57 \%$ \\
\hline Caramel & Balsamic, Plum, Dark beer, Cooked must & 39 & $56 \%$ \\
\hline Leather & Tannin, Urine, Farm, Stable & 38 & $54 \%$ \\
\hline Drug & Glue, Vinegar, Acetic acid, Camphor, Chemical, Incense, Mothball, Paint & 37 & $53 \%$ \\
\hline Vanilla & Christmas cake, Cappuccino, Chocolate hazelnut & 36 & $51 \%$ \\
\hline Tobacco & Cocoa, Coffee, The, Chocolate, Hay & 35 & $50 \%$ \\
\hline Smoked & Rhubarb, spices & 34 & $49 \%$ \\
\hline Meat broth & Cooked, Fish, Soy sauce & 32 & $46 \%$ \\
\hline Grass cut & Poppy, Green tomato, Tomato leaf, Green pepper & 31 & $44 \%$ \\
\hline Molasses & Wax, Candied fruit, Raisin, Honey, Wine & 29 & $41 \%$ \\
\hline Bitter almond & Coriander & 28 & $40 \%$ \\
\hline Apple & Banana, Red fruit, Strawberry, Cherry, Unripe fruit & 28 & $40 \%$ \\
\hline Glue & Drug, Vinegar, Acetic acid, Camphor, Chemical, Incense, Mothball, Paint & 26 & $37 \%$ \\
\hline Clove & Nutmeg, Cinnamon, Pepper, Horseradish, Spices & 26 & $37 \%$ \\
\hline Chocolate & Cocoa, Coffee, The, Hay, Tobacco & 25 & $36 \%$ \\
\hline Banana & Apple, Red fruit, Strawberry, Cherry, Unripe fruit & 25 & $36 \%$ \\
\hline Mildew & Rotten, Moss & 25 & $36 \%$ \\
\hline Honey & Wax, Candied fruit, Raisin, Molasses, Wine & 24 & $34 \%$ \\
\hline Pepper & Nutmeg, Cinnamon, Clove, Horseradish, Spices & 24 & $34 \%$ \\
\hline Rancid & & 22 & $31 \%$ \\
\hline Bran & Cereals, Malt & 21 & $30 \%$ \\
\hline Bread crust & Bread, Alcohol, Flour, Yeast, Toasted & 19 & $27 \%$ \\
\hline Yeast & Bread crust, Bread, Alcohol, Flour, Toasted & 19 & $27 \%$ \\
\hline Boiled cabbage & Savoy cabbage, Corn, Boiled potato & 18 & $26 \%$ \\
\hline Cheese & Corn silage, Acid, Olive, Pungent, Vomit, Sweat, Milk, Yogurt & 17 & $24 \%$ \\
\hline Coffee & Cocoa, Tobacco, Tea, Chocolate, Hay & 14 & $20 \%$ \\
\hline Flour & Bread crust, Bread, Alcohol, Toasted, Yeast & 12 & $17 \%$ \\
\hline Cocoa & Chocolate, Tobacco, Tea, Hay, Coffee & 10 & $14 \%$ \\
\hline Pop corn & Peanuts, Butter & 8 & $11 \%$ \\
\hline Anise & Licorice, Mint, Ginger, Tarragon, Dry orange peel, Lemon, Menthol & 8 & $11 \%$ \\
\hline Boiled potato & Savoy cabbage, Corn, Boiled cabbage & 5 & $7 \%$ \\
\hline Broth & Broth, Cooked, Fish, Soy sauce & 4 & $6 \%$ \\
\hline Wood & Sawdust, Cork & 4 & $6 \%$ \\
\hline
\end{tabular}




\section{References}

1. Chen F, Li L, Qu J, Chen C. Cereal vinegars made by solid-state fermentation in China. Vinegars of the World 2009;243-59.

2. Liu D, Zhu Y, Beeftink R, et al. Chinese vinegar and its solidstate fermentation process. Food Rev Int 2004;20:407-24.

3. Zhao L, Li L. The history, present status, development trend of the production technology of Chinese vinegar. Chinese Condiment 2005.

4. Huang Z, Cai M. Vinegar. In: The production technology of fermented condiments. Beijing: Light Industry Publishing House of China; 1999. pp 289-419.

5. Tesfaye W, García-Parrilla MC, Troncoso AM. Sensory evaluation of Sherry wine vinegar. J Sens Stud 2002;17:133-44.

6. Giudici P, Falcone P, Scacco A, Lanza C. Sensory analysis of the traditional balsamic vinegar. Ind Bevande 2009;224:27-42.

7. Morales Gómez ML, Bellido BB, Tesfaye W, et al. Sensory evaluation of Sherry vinegar: traditional compared to accelerated aging with oak chips. J Food Sci 2006;71:238-42.

8. Tesfaye W, Morales ML, Callejón RM, et al. Descriptive sensory analysis of wine vinegar: tasting procedure and reliability of new attributes. J Sens Stud 2010;25:216-30.

9. Callejón RM, Morales ML, Ferreira ACS, Troncoso AM. Defining the typical aroma of Sherry vinegar: sensory and chemical approach. J Agric Food Chem 2008;56:8086-95.

10. Ren H, Endo H, Watanabe E, Hayashi T. Chemical and sensory characteristics Chinese, Korean, and Japanese vinegars. J Tokyo Univ Fish 1997;84:1-11.

11. Corradini G, Lemmetti F, Giudici P. Wine and balsamics vine- gars: olfactory and chemesthetic attributes; sensory active substances. Ind Aliment 2016 [Epub ahead of print].

12. Murray J, Delahunty C, Baxter I. Descriptive sensory analysis: past, present and future. Food Res Int 2001;34:461-71.

13. ISO 11035: Sensory analysis methodology - identification and selection of descriptors for establishing a sensory profile by a multidimensional approach; 1994.

14. Drake MA, Mcingvale SC, Gerard PD, Cadwallader KR, Civille GV. Development of a descriptive language for Cheddar cheese. J Food Sci 2001;66:1422-7.

15. Civille G, Dus C. Evaluating tactile properties of skincare products: a descriptive analysis technique. Cosmet Toilet 1991;106:83-8.

16. N'Kouka K, Klein B, Lee S. Developing a lexicon for descriptive analysis of soymilks. J Food Sci 2004;69:259-63.

17. Galán-Soldevilla H, Ruiz-Pérez-Cacho MP, Serrano Jiménez S, et al. Development of a preliminary sensory lexicon for floral honey. Food Qual Prefer 2005;16:71-7.

18. Lee J, Chambers DH. A lexicon for flavor descriptive analysis of green tea. J Sens Stud 2007;22:256-72.

19. Bérodier F, Lavanchy P, Zannoni M, et al. Guide d'évaluation olfacto-gustative des fromages à pâte dure et semi-dure. LWT Food Sci Technol 1997;30:653-64.

20. Hellemann U, Tuorila H, Salovaara H. Sensory profiling and multidimensional scaling of selected Finnish rye breads. Int J Food Sci Tech 1987;22:693-700.

21. ISO 6658: Sensory analysis Methodology - General guidance; 2005. 